\title{
Comparison of time and cost between conventional surgical planning and virtual surgical planning in orthognathic surgery in Korea
}

\author{
Si-Yeon Park ${ }^{1}$, Dae-Seok Hwang ${ }^{1,2^{*}}$ D, Jae-Min Song ${ }^{1}$ and Uk-Kyu Kim ${ }^{1}$
}

\begin{abstract}
Background: The purpose of this study was to measure the time of the conventional surgical planning (CSP) and virtual surgical planning (VSP) in orthognathic surgery and to compare them in terms of cost.

Material and method: This is a retrospective study of the patients who underwent orthognathic surgery at the O0000 University Dental Hospital from December 2017 to August 2018. All the patients were analyzed through both CSP and VSP, and all the surgical stents were fabricated through manual and 3-dimensional (3D) printing. The predictor variables were the planning method (CSP vs. VSP) and the surgery type (group I: Le Fort I osteotomy+bilateral sagittal split osteotomy [LFI+BSSO] or group II: only bilateral sagittal split osteotomy [BSSO]), and the outcomes were the time and cost. The results were analyzed using paired t test.

Results: Thirty patients (12 females, 18 males) met the inclusion criteria, and 17 patients were excluded from the study due to missing or incomplete data. There were 20 group I patients (LFI+BSSO regardless of genioplasty) and 10 group II patients (BSSO regardless of genioplasty). The average time of CSP for group I was $385 \pm 7.8 \mathrm{~min}$, and that for group II was $195 \pm 8.33 \mathrm{~min}$. The time reduction rate of VSP compared with CSP was $62.8 \%$ in group I and $41.5 \%$ in group II. On the other hand, there was no statistically significant cost reduction.
\end{abstract}

Conclusions: The time investment in VSP in this study was significantly smaller than that in CSP, and the difference was greater in group I than in group II.

Keywords: Conventional surgical planning, Virtual surgical planning, Orthognathic surgery

\section{Background}

It is obvious that accurate and delicate patient analysis must precede successful orthognathic surgery. A patient analysis is done through thorough patient data analysis.

Conventional surgical planning (CSP) is based on the patient's facial photographs, deformity analysis through a two-dimensional (2D) cephalometric

\footnotetext{
* Correspondence: dshwang@pusan.ac.kr

'Department of Oral and Maxillofacial Surgery, School of Dentistry, Pusan National University, Busandaehak-ro, Mulgeum-eup, Yangsan 50612, Republic of Korea

${ }^{2}$ Dental Research Institute, Pusan National University Dental Hospital, Busandaehak-ro, Mulgeum-eup, Yangsan 50612, Republic of Korea
}

tracing, mounted cast analysis using facebow transfer, and model surgery. At first, a resident made a surgical stent based on the model surgery. At present, however, the surgeons request a laboratory to fabricate a surgical stent after sending to it the mounted cast and the surgical plan.

With the development of cone beam computed tomography $(\mathrm{CBCT})$ and of the computer-aided design and computer-aided manufacturing (CAD-CAM) technology, the virtual surgical planning (VSP) method for 3D planning and analysis has been expanding of late. VSP consists of analyzing the patient's skeletal deformity with a 3D analysis program
Springer Open (c) The Author(s). 2021 Open Access This article is licensed under a Creative Commons Attribution 4.0 International License, which permits use, sharing, adaptation, distribution and reproduction in any medium or format, as long as you give appropriate credit to the original author(s) and the source, provide a link to the Creative Commons licence, and indicate if changes were made. The images or other third party material in this article are included in the article's Creative Commons licence, unless indicated otherwise in a credit line to the material. If material is not included in the article's Creative Commons licence and your intended use is not permitted by statutory regulation or exceeds the permitted use, you will need to obtain permission directly from the copyright holder. To view a copy of this licence, visit http://creativecommons.org/licenses/by/4.0/. 
using $\mathrm{CBCT}$, performing virtual surgery, and then fabricating a surgical stent using a $3 \mathrm{D}$ printing machine.

Many studies have shown that VSP has higher accuracy than 2D CSP, and the 3D analysis program that is used in it has become diversified and popularized [1-6]. It is continuously reported that VSP not only has higher accuracy, but it has a shorter time and a lower cost than CSP [7-9].

This study was conducted to determine if the time and the cost difference between VSP and CSP in South Korea are the same as that reported in other countries.

\section{Patients and methods}

\section{Study design and patients}

This is a retrospective study of patients who underwent orthognathic surgery at Pusan National University Dental Hospital from December 2017 to August 2018. Patients who [1] underwent both Le Fort I osteotomy and bilateral sagittal split osteotomy (LFI+BSSO) or only bilateral sagittal split osteotomy (BSSO) were enrolled in the study. Genioplasty was not considered. In addition, [2] preoperative preparation was performed in the oral and maxillofacial surgery (OMS) department of the authors' hospital, and [3] surgical planning was done through both CSP and VSP. The patients with a craniofacial deformity (e.g., cleft lip and palate) and those with a previous history of head trauma or with a systemic disease were excluded from the study. The patients were divided into two groups: group I, which included patients who had undergone both LFI and BSSO regardless of genioplasty, and group II, which included patients who had undergone BSSO regardless of genioplasty.

This study was reviewed by the Institutional Review Board (IRB) of OOOOOO and was approved after thorough deliberation (OOOOO-2019-002).

\section{Progress workflow in CSP vs VSP}

All the patients underwent radiography (panorama, lateral cephalogram, posterio-anterior cephalogram, and cone beam computed tomography (CBCT)). Clinical photographs of them were also taken, and they were interviewed. All the cases were analyzed using both CSP and VSP.

In group I, two pairs of maxillary and mandibular impression, and facebow transfer, were needed for CSP. Impression and pouring were done by an intern, and facebow transfer was done by 2 -year residents (R2). The radiographs were analyzed by $\mathrm{R} 2$ using the 2D analysis program V-ceph. (version 6.0; Osstem, Seoul, South Korea). Then, Hanau articulator mounting and simple articulator mounting were performed by an intern.
In group II, only one pair of maxillary and mandibular impression was needed for CSP, and facebow transfer was not needed. The other steps were the same as with group I.

The mounted casts and final occlusion were then sent to a laboratory, and the dental technician made an intermediate stent (group I only) and a final stent based on the surgical plan [Fig. 1].

In both groups I and II, only one pair of maxillary and mandibular impression was needed for VSP, and facebow transfer was not needed. The obtained CBCT image was analyzed by an R2 using the in vivo 3D imaging software (version 6.0; Anatomage, San Jose, $\mathrm{CA}$ ), and mounted casts and the final occlusion images were sent to a 3D printing laboratory (TRUEM Inc., Seoul, South Korea). VSP was completed with a case confirmation web meeting between the surgeon and the technician through a virtual operated model (Fig. 2). The 3D printing laboratory fabricated an intermediate stent (group I only) and a final stent using the $3 \mathrm{D}$ printing process, based on the surgical plan (Fig. 3, Table 1).

\section{Time and cost analysis}

All the steps were timed and recorded, and the times of all the steps were averaged. The cost was analyzed by calculating the hourly rate based on the average annual salary by occupation announced by the Korea Research Institute for the 2012 Vocational Education and Training Analysis of Continuing Professional Education (CPE) for Licensed National Qualifications [10]. The hourly rate (South Korean won: KRW per hour) was 42,830 KRW for the dentist, 12,390 KRW for the dental hygienist, and 14,540 KRW for the dental technician. The total cost was derived by multiplying the hourly cost by the work time depending on the occupation of the conductor in each process. The cost of stent fabrication includes the cost of software, hardware, and material used in the process at the outsourced laboratory.

\section{Statistical analysis}

The differences between the groups were compared via paired $\mathrm{t}$ test. $\mathrm{P}<0.05$ was considered to indicate statistical significance. All the data were analyzed using the SPSS software (23.0; SPSS, Chicago, IL).

\section{Results}

A total of 47 patients underwent orthognathic surgery by one surgeon in the authors' department during the study period. Thirty patients ( 12 females, 18 males) met the inclusion criteria, and 17 patients were excluded due to missing or incomplete data. There were 20 group I patients (LFI+BSSO regardless of genioplasty) and 10 

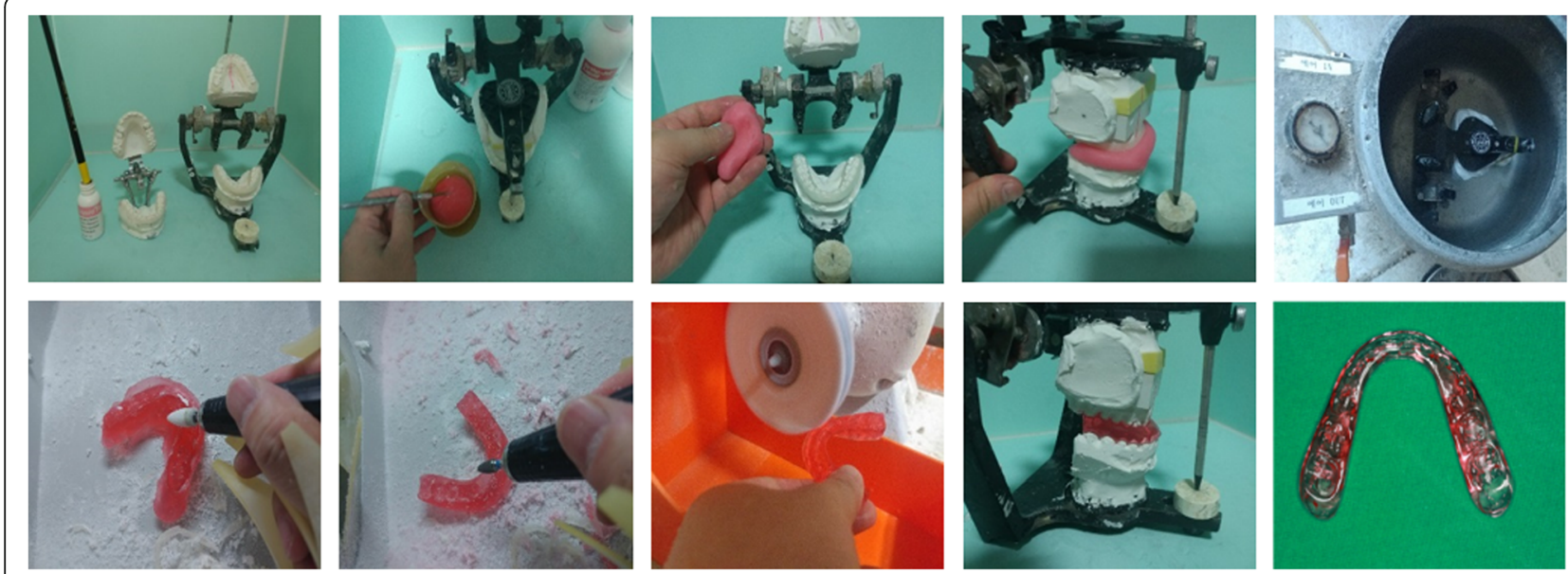

Fig. 1 Stent fabrication progress in conventional surgical planning

group II patients (BSSO regardless of genioplasty). Two different dental hygienists, four technicians (2 radiographers, 2 dental technicians), six 2 -year residents (R2), and eight interns were involved in the cases. The average times of all the steps in the workflow of CSP and VSP for groups I and II are shown in Table 2. Overall, VSP takes less time than CSP. The average time of CSP in group I was $385 \pm$ $7.8 \mathrm{~min}$ and that in group II was $195 \pm 8.33 \mathrm{~min}$. The average time of VSP in group I was $143.2 \pm 7.6$ $\mathrm{min}$ and that in group II was $114.1 \pm 7.12 \mathrm{~min}$ [Table $2]$. When the time reduction rates were compared by category, it was found to be highest in the laboratory process. In group I, the time reduction rate was negative at the office workup step, and VSP seems to have taken longer, but the difference was not statistically significant (Table 3 ). The average cost of CSP in group I was 805,015 KRW and that in group II was 508,061 KRW. As for VSP, its average cost in group I was $885,905 \mathrm{KRW}$, and that in group II was 624,267 KRW (Table 4). The overall cost reduction rate was $-9.1 \%$ in group 1 and $-18.6 \%$ in group 2 , and the cost reduction rates by category are shown in Table 5.

\section{Discussion}

CSP is often carried out manually; thus, errors and distortions often occur. For example, the impression accuracy may vary depending on the impression material mixing time, the mixing temperature, and the work time during impression, and the accuracy of the facebow transfer may vary depending on the skill of the operator and the degree of patient cooperation [11, 12]. VSP is emerging as a way of reducing errors and improving the accuracy of the surgical planning process. It is much more accurate than CSP because it involves virtual surgery and surgical stent fabrication using $\mathrm{CBCT}[5,6$, 13-16]. Due to the high accuracy of VSP, OMS surgeons use it more often than CSP when performing maxillofacial reconstruction as well as orthognathic surgery. Some studies have pointed out, however, that the cost of VSP is higher than that of CSP [17-19].

This study was conducted to compare the time and cost investments in CSP and VSP in planning orthognathic surgery in South Korea. Wrozosek et al. and Resnick et al. hypothesized that VSP is more time- and cost-efficient than CSP [7, 9]. These authors aimed to categorize each step of the surgical plan between the

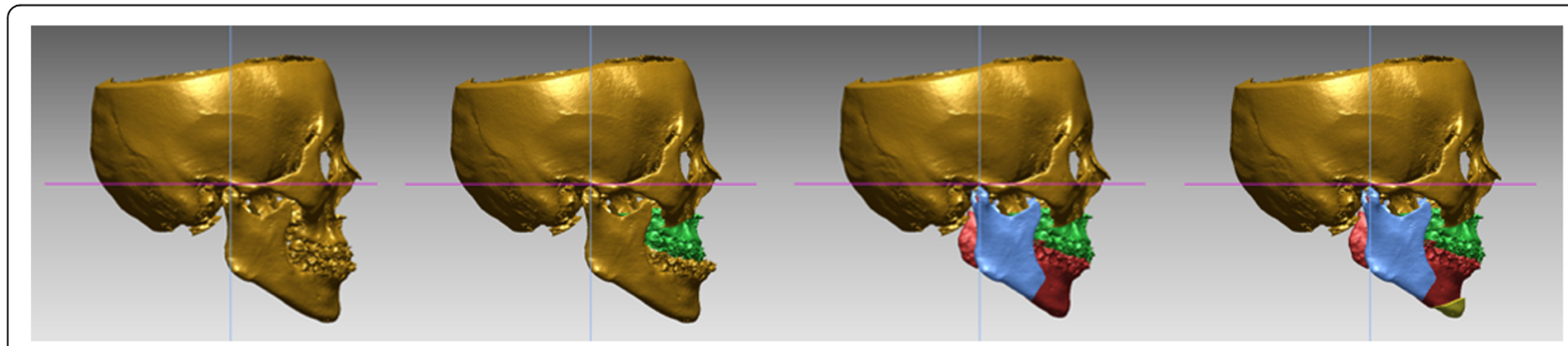

Fig. 2 Virtual surgery in virtual surgical planning 
Table 1 Progress workflow and performer for CSP and VSP

\begin{tabular}{|c|c|c|c|c|c|}
\hline & \multicolumn{2}{|l|}{ CSP } & \multicolumn{2}{|l|}{ VSP } & Performer \\
\hline \multirow[t]{2}{*}{ Outpatient workup } & \multicolumn{4}{|c|}{$\begin{array}{l}\text { Clinical photograph } \\
\text { 2D radiography (panorama, Lat-cephalogram, PA-cephalogram) } \\
\text { Cone beam computed tomography (CBCT) } \\
\text { Interview }\end{array}$} & \multirow[t]{2}{*}{$\begin{array}{l}\text { Dental hygienist } \\
\text { Technician } \\
\text { Resident }\end{array}$} \\
\hline & Group I & Group ॥ & Group I & Group II & \\
\hline $\begin{array}{l}\text { Impression } \\
\text { (pairs) }\end{array}$ & 2 & 1 & 1 & & Intern \\
\hline Facebow transfer & Yes & No & No & & Resident \\
\hline Bite registration & 2 & 1 & 1 & & Intern \\
\hline \multirow[t]{3}{*}{ Office workup } & \multicolumn{2}{|c|}{ Import Lat.-cephalogram } & \multicolumn{2}{|c|}{ Import CBCT } & \\
\hline & \multicolumn{2}{|c|}{ Trace 2D Lat.-cephalogram } & \multicolumn{2}{|c|}{ Trace 3D CBCT } & Resident \\
\hline & \multicolumn{2}{|l|}{ 2D surgical planning } & \multicolumn{2}{|c|}{ 3D surgical planning } & \\
\hline Mounting & $\begin{array}{l}\text { Hanau articulator } \\
\text { Simple articulator }\end{array}$ & Simple articulator & \multicolumn{2}{|c|}{ Simple articulator } & Intern \\
\hline Laboratory & \multicolumn{2}{|l|}{ Model surgery } & \multicolumn{2}{|c|}{ Virtual surgery } & \\
\hline Case confirm & No & & Yes & No & Resident/technician \\
\hline Stent fabrication & \multicolumn{2}{|l|}{ Manual fabrication } & \multicolumn{2}{|c|}{ 3D printing } & \\
\hline
\end{tabular}

Abbreviations: CSP conventional surgical planning; VSP virtual surgical planning; 2D 2-dimensional; 3D 3-dimentional; Lat. cephalogram, lateral-cephalogram; PA cephalogram, posterio-anterior cephalogram

two groups and to measure and compare the times of CSP and VSP.

In terms of the total time, that of VSP was much shorter than that of CSP in both groups in this study, and the time reduction rate was larger in group I than in group II [Table 2]. This is because the processes of CSP and VSP are similar in group II, and the process of CSP in group I is largely omitted in VSP. In the office workup category in group I, the time reduction rate was negative. The difference, however, was statistically insignificant, and it can thus be concluded that CSP and VSP are similar in terms of the time to the office workup. This is similar to the results of the study of Steinhuber et al., where the time for analyzing the patients and that for planning the surgery was similar regardless of the type of program used by the OMS residents, [8] as the planning is done by the patient's characteristic and knowledge of surgeon's rather than the method used.
Since the total cost of VSP was much higher than CSP in both groups, it seems likely to consider VSP was not effective in both groups (Table 4). The reason why the cost of VSP was higher than CSP was that the stent was fabricated in an outsourced laboratory instead of fabricating the stent in a dental hospital. However, when the labor cost of residents and interns was considered, the cost of VSP was much lower than CSP. Therefore, from the OMS surgeon's point of view, when comparing all of these factors, VSP is more cost-effective than CSP.

It was found that relatively complex surgery was more time-effective than relatively simple surgery in group I; as such, it is concluded that the more complex the surgery is, the more time-effective VSP is. Otherwise, in the case of relatively simple surgery, it can be concluded that CSP is more cost-effective than VSP.

A law for the improvement of the residents' training environment and status was recently established in South Korea. The law ensures that residents do not work
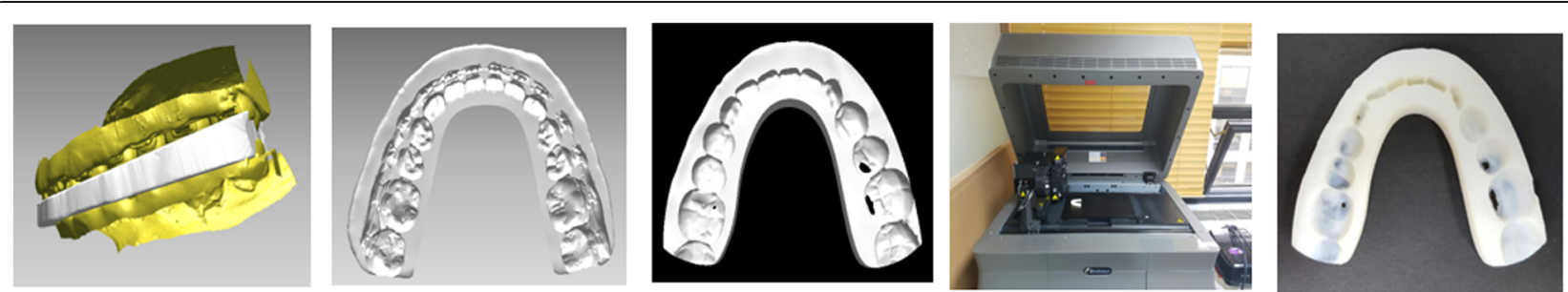

Fig. 3 Stent fabrication progress in virtual surgical planning 
Table 2 Average time for each step in CSP and VSP

\begin{tabular}{|c|c|c|c|c|c|}
\hline \multirow[t]{2}{*}{ Category } & \multirow[t]{2}{*}{ Step } & \multicolumn{2}{|l|}{ CSP } & \multicolumn{2}{|l|}{ VSP } \\
\hline & & Group I & Group ॥ & Group I & Group II \\
\hline \multirow[t]{6}{*}{ Outpatient workup } & Clinical photograph & $7.76 \pm 0.3$ & & & \\
\hline & $2 \mathrm{D}$ radiography and $\mathrm{CBCT}$ & $5.32 \pm 0.21$ & & & \\
\hline & Interview & $10.09 \pm 1.15$ & & & \\
\hline & Impression & $44.62 \pm 3.57$ & $23.42 \pm 3.5$ & $22.57 \pm 3.5$ & \\
\hline & Facebow transfer & $2.69 \pm 0.38$ & - & - & - \\
\hline & Bite registration & $1.55 \pm 0.16$ & $0.75 \pm 0.15$ & $0.71 \pm 0.15$ & \\
\hline Subtotal & & $74.3 \pm 4.03$ & $48.6 \pm 2.56$ & $48.3 \pm 2.61$ & \\
\hline \multirow[t]{3}{*}{ Office workup } & Surgical planning & $23.33 \pm 1.89$ & $20.15 \pm 1.89$ & $30.20 \pm 1.60$ & $25.13 \pm 1.60$ \\
\hline & Mounting (Hanau articulator) & $8.23 \pm 2.09$ & - & - & - \\
\hline & Mounting (Simple articulator) & $3.95 \pm 1.19$ & $3.82 \pm 1.15$ & $3.73 \pm 1.02$ & $3.87 \pm 1.09$ \\
\hline Subtotal & & $34.4 \pm 3.12$ & $24.5 \pm 2.11$ & $35.2 \pm 1.78$ & $29.4 \pm 1.81$ \\
\hline \multirow[t]{2}{*}{ Laboratory } & Case confirm & - & - & $8.93 \pm 1.15$ & $6.38 \pm 1.15$ \\
\hline & Stent fabrication & $296 \pm 6.7$ & $123 \pm 5.6$ & $59.71 \pm 2.21$ & $31.24 \pm 1.71$ \\
\hline Subtotal & & $296 \pm 6.7$ & $123 \pm 5.6$ & $68.93 \pm 3.2$ & $36.38 \pm 2.7$ \\
\hline Total & & $385 \pm 7.8$ & $195 \pm 8.33$ & $143.2 \pm 7.6$ & $114.1 \pm 7.12$ \\
\hline
\end{tabular}

Abbreviations: CSP conventional surgical planning, VSP virtual surgical planning, 2D 2-dimentional, 3D 3-dimentional, $C B C T$ cone beam computed tomography

for more than $80 \mathrm{~h}$ a week and have at least 1 day off per week. VSP does not significantly reduce the office workup time, but it saves on the resident work time by significantly reducing the laboratory work time. The transition from CSP to VSP in surgery planning can be said to be in accordance with the above trend. Many studies have shown that VSP has high accuracy, and it was also shown in this study that it is more timeeffective than CSP in South Korea.
Even if VSP is more effective compared to CSP, it still has cost disadvantages due to the high cost of processing its software and hardware. However, when the number of surgeons and hospitals using VSP for their surgery increases, there will be more outsourced laboratories and systems available at a lower cost. Therefore, VSP will eventually be available in a more effective way and it will also increase the accuracy of orthognathic surgery in South Korea.

Table 3 Time reduction rate for each category in VSP comparing with CSP

\begin{tabular}{|c|c|c|c|}
\hline Category & Step & Group I (\%) & Group II (\%) \\
\hline \multirow[t]{6}{*}{ Outpatient workup } & Clinical photograph & - & \\
\hline & $2 \mathrm{D}$ radiography and $\mathrm{CBCT}$ & & \\
\hline & Interview & & \\
\hline & Impression & $49.0^{*}$ & 3.6 \\
\hline & Facebow transfer & $100.0^{*}$ & - \\
\hline & Bite registration & $54.2^{*}$ & 5.4 \\
\hline Subtotal & & $35.0^{*}$ & 1.6 \\
\hline \multirow[t]{3}{*}{ Office workup } & Surgical planning & -1.3 & -1.25 \\
\hline & Mounting (Hanau articulator) & $100.0^{*}$ & - \\
\hline & Mounting (simple articulator) & 5.6 & -1.0 \\
\hline Subtotal & & -2.3 & $14.8^{*}$ \\
\hline \multirow[t]{2}{*}{ Laboratory } & Case confirm & -100 & -100 \\
\hline & Stent fabrication & $79.8^{*}$ & $74.6^{*}$ \\
\hline Subtotal & & $76.7^{*}$ & $70.4^{*}$ \\
\hline Total & & $62.8^{*}$ & $41.5^{*}$ \\
\hline
\end{tabular}

Abbreviations: CSP conventional surgical planning, VSP virtual surgical planning * Statistically significant $(P<0.01)$ 
Table 4 Total cost for each group in CSP and VSP

\begin{tabular}{|c|c|c|c|c|c|}
\hline \multirow[t]{2}{*}{ Category } & \multirow[t]{2}{*}{ Step } & \multicolumn{2}{|l|}{ CSP } & \multicolumn{2}{|l|}{ VSP } \\
\hline & & Group I & Group ॥ & Group I & Group II \\
\hline \multirow[t]{6}{*}{ Outpatient workup } & Clinical photograph & 1602 & & & \\
\hline & $2 \mathrm{D}$ radiography and $\mathrm{CBCT}$ & 1289 & & & \\
\hline & Interview & 7203 & & & \\
\hline & Impression & 31,851 & 16,718 & 16,111 & \\
\hline & Facebow transfer & 1920 & - & - & - \\
\hline & Bite registration & 1106 & 535 & 507 & \\
\hline Subtotal & & 44,972 & 27,348 & 26,712 & \\
\hline \multirow[t]{3}{*}{ Office workup } & Surgical planning & 16,654 & 14,384 & 21,558 & 17,939 \\
\hline & Mounting (Hanau articulator) & 5875 & - & - & - \\
\hline & Mounting (simple articulator) & 2820 & 2727 & 2663 & 2763 \\
\hline Subtotal & & 25,348 & 17,111 & 24,220 & 20,701 \\
\hline \multirow[t]{2}{*}{ Laboratory } & Case confirm & - & - & 6375 & 4554 \\
\hline & Stent fabrication & 211,295 & 87,802 & 48,998 & 22,300 \\
\hline Stent cost & & 523,400 & 375,800 & 779,600 & 550,000 \\
\hline Subtotal & & 734,695 & 463,602 & 834,973 & 576,854 \\
\hline Total cost, KRW & & 805,015 & 508,061 & 885,905 & 624,267 \\
\hline
\end{tabular}

Abbreviations: CSP conventional surgical planning, VSP virtual surgical planning, KRW South Korea Won

In this study, each step of VSP and CSP was not performed in the same place. Since it was performed separately, it is possible that its accuracy and costeffectiveness decreased when it was processed in different laboratories. As a result, if the hospital is well equipped with software and hardware, each step of VSP and CSP can be performed in the same hospital and it will increase the cost-effectiveness and accuracy of the process by reducing errors and extra charges from the outsourced laboratory.

Table 5 Cost reduction rate for each category in VSP comparing with CSP

\begin{tabular}{|c|c|c|c|}
\hline Category & Step & Group I (\%) & Group II (\%) \\
\hline \multirow[t]{6}{*}{ Outpatient workup } & Clinical photograph & - & \\
\hline & $2 \mathrm{D}$ radiography and $\mathrm{CBCT}$ & & \\
\hline & Interview & & \\
\hline & Impression & $49.6^{*}$ & 3.6 \\
\hline & Facebow transfer & $100^{*}$ & \\
\hline & Bite registration & $54.2^{*}$ & 5.2 \\
\hline Subtotal & & $40.6^{*}$ & 2.3 \\
\hline \multirow[t]{3}{*}{ Office workup } & Surgical planning & $-22.7^{*}$ & $-20.2^{*}$ \\
\hline & Mounting (Hanau articulator) & $100^{*}$ & - \\
\hline & Mounting (simple articulator) & 5.6 & -0.001 \\
\hline Subtotal & & 4.5 & -17.3 \\
\hline \multirow[t]{2}{*}{ Laboratory } & Case confirm & $-100^{*}$ & $-100^{*}$ \\
\hline & Stent fabrication & $76.8^{*}$ & $74.6^{*}$ \\
\hline Stent cost & & $-32.9^{*}$ & $-31.7^{*}$ \\
\hline Subtotal & & -12.0 & $-19.7^{*}$ \\
\hline Total & & -9.1 & $-18.6^{*}$ \\
\hline
\end{tabular}

Abbreviations: CSP conventional surgical planning, VSP virtual surgical planning *Statistically significant $(P<0.01)$ 


\section{Conclusion}

In conclusion, this study showed that VSP is more timeeffective than CSP in South Korea, as is the case in other countries. With its high accuracy and time efficiency, VSP is the future for orthognathic surgery planning. As the VSP program continues to evolve, research on how to reduce the work time and cost for each step should be done.

\section{Abbreviations}

CSP: Conventional surgical planning; VSP: Virtual surgical planning; LFI: Le Fort I osteotomy; BSSO: Bilateral sagittal split osteotomy; 2D: Two dimensions; 3D: Three dimensions; CBCT: Cone beam computed tomography; CAD-CAM: Computer-aided design and computer-aided manufacturing; OMS: Oral and maxillofacial surgery

\section{Acknowledgements}

Not applicable

\section{Authors' contributions}

Dae-Soek Hwang participated in the design of this study and manuscript revision, and Uk-kyu Kim and Jae-Min Song participated in the fabrication of the new material. Si-Yeon Park performed the study and data collection. SiYeon Park and Jae-Min Song participated in the data analysis and drafted the manuscript. The authors read and approved the final manuscript.

\section{Funding}

There was no financial support.

\section{Availability of data and materials}

Readers interested in the data should contact the authors.

\section{Declarations}

\section{Ethics approval and consent to participate}

This study was reviewed by the Institutional Review Board (IRB) of Pusan National University Dental Hospital and was approved after thorough deliberation. IRB number: PNUDH-2019-002

\section{Consent for publication}

This manuscript does not contain any individual person's identifier (including individual details, images, or videos).

\section{Competing interests}

The authors declare that they have no competing interests.

Received: 31 May 2019 Accepted: 12 August 2019

Published online: 21 June 2021

\section{References}

1. Zhang N, Liu S, Hu Z, Hu J, Zhu S, Li Y (2016) Accuracy of virtual surgical planning in two-jaw orthognathic surgery: comparison of planned and actual results. Oral Surg Oral Med Oral Pathol Oral Radiol Endod 122(2):143151. https://doi.org/10.1016/j.0000.2016.03.004

2. Kwon TG, Choi JW, Kyung HM, Park HS (2014) Accuracy of maxillary repositioning in two-jaw surgery with conventional articulator model surgery versus virtual model surgery. Int J Oral Maxillofac Surg 43(6):732738. https://doi.org/10.1016/j.ijom.2013.11.009

3. Ritto FG, Schmitt ARM, Pimentel T, Canellas JV, Medeiros PJ (2018) Comparison of the accuracy of maxillary position between conventional model surgery and virtual surgical planning. Int J Oral Maxillofac Surg 47(2): 160-166. https://doi.org/10.1016/j.ijom.2017.08.012

4. Jaisinghani S (2017) et al. Virtual Surgical Planning in Orthognathic Surgery. Eplasty 17

5. Farrell BB, Franco PB, Tucker MR (2014) Virtual surgical planning in orthognathic surgery. Oral Maxillofac Surg Clinics 26(4):459-473. https://doi. org/10.1016/j.coms.2014.08.011
6. Swennen GRJ (2017) 3D virtual treatment planning of orthognathic surgery. In: 3D Virtual Treatment Planning of Orthognathic Surgery. Springer, Berlin, Heidelberg, pp 217-277

7. Resnick CM, Inverso G, Wrzosek M, Padwa BL, Kaban LB, Peacock ZS (2016) Is there a difference in cost between standard and virtual surgical planning for orthognathic surgery? J Oral Maxillofac Surg 74(9):1827-1833. https://doi. org/10.1016/j.joms.2016.03.035

8. Steinhuber T, Brunold S, Gärtner C, Offermanns V, Ulmer H, Ploder O (2018) Is virtual surgical planning in orthognathic surgery faster than conventional planning? A time and workflow analysis of an office-based workflow for single-and double-jaw surgery. J Oral Maxillofac Surg 76(2):397-407. https:// doi.org/10.1016/j.joms.2017.07.162

9. Wrzosek MK, Peacock ZS, Laviv A, Goldwaser BR, Ortiz R, Resnick C et al (2016) Comparison of time required for traditional versus virtual orthognathic surgery treatment planning. Int J Oral Maxillofac Surg 45(9): 1065-1069. https://doi.org/10.1016/j.ijom.2016.03.012

10. Kim, et al. Analysis of Continuing Professional Education (CPE) for licensed national qualifications. Korea Research Institute for Vocational Education and Training, 2012

11. Zille. Devid. The evolution of surgical planning in orthognathic surgery. EC Dental Science 2018;17.11:1914-1919.

12. Ellis III (1990) Edward Accuracy of model surgery: evaluation of an old technique and introduction of a new one. J Oral Maxillofac Surg 48(11): 1161-1167. https://doi.org/10.1016/0278-2391(90)90532-7

13. Hsu SS-P, Gateno J, Bell RB, Hirsch DL, Markiewicz MR, Teichgraeber JF, Zhou X, Xia JJ (2013) Accuracy of a computer-aided surgical simulation protocol for orthognathic surgery: a prospective multicenter study. J Oral Maxillofac Surg 71(1):128-142. https://doi.org/10.1016/j.joms.2012.03.027

14. Iorio ML, Masden D, Blake CA, Baker SB (2011) Presurgical planning and time efficiency in orthognathic surgery: the use of computer-assisted surgical simulation. Plast Reconstr Surg 128.3:179e-181e

15. Schwartz HC (2014) Does computer-aided surgical simulation improve efficiency in bimaxillary orthognathic surgery? Int J Oral Maxillofac Surg 43(5):572-576. https://doi.org/10.1016/j.jjom.2013.10.018

16. Stokbro K, Aagaard E, Torkov P, Bell RB, Thygesen T (2014) Virtual planning in orthognathic surgery. Int J Oral Maxillofac Surg 43(8):957-965. https://doi. org/10.1016/j.jijom.2014.03.011

17. Hanasono MM, Skoracki RJ (2013) Computer-assisted design and rapid prototype modeling in microvascular mandible reconstruction. Laryngoscope 123(3):597-604. https://doi.org/10.1002/lary.23717

18. Tepper O, Hirsch D, Levine J, Garfein E (2012) The new age of threedimensional virtual surgical planning in reconstructive plastic surgery. Plast Reconstr Surg 130:192-194

19. Rodby KA, Turin S, Jacobs RJ, Cruz JF, Hassid VJ, Kolokythas A, Antony AK (2014) Advances in oncologic head and neck reconstruction: systematic review and future considerations of virtual surgical planning and computer aided design/computer aided modeling. J Plast Reconstr Aesthet Surg 67(9): 1171-1185. https://doi.org/10.1016/j.bjps.2014.04.038

\section{Publisher's Note}

Springer Nature remains neutral with regard to jurisdictional claims in published maps and institutional affiliations.

\section{Submit your manuscript to a SpringerOpen ${ }^{\circ}$ journal and benefit from:}

- Convenient online submission

- Rigorous peer review

- Open access: articles freely available online

- High visibility within the field

Retaining the copyright to your article

Submit your next manuscript at $>$ springeropen.com 